\title{
Controle alternativo de podridões pós-colheita em tomate
}

O Brasil é um dos grandes produtores de tomate, porém a maior parte da produção destina-se ao consumo interno por não se enquadrar nos padrões internacionais. Neste estudo foi avaliado o efeito de óleos essenciais sobre parâmetros físico-químicos, bem como no controle de patógenos pós-colheita em frutos de tomateiro. Os tratamentos avaliados foram Cantus ${ }^{\circledR}$ (testemunha positiva), água destilada (testemunha negativa), óleos essenciais a $1 \%$ de Alecrim (Rosmarinus officinalis), Canela (Cinnamomum zeylanicum), Cravo-da-índia (Caryophillus aromaticus), Copaíba (Copaifera sp.). Os frutos foram imergidos nos tratamentos, incubados em câmara úmida por 24 horas e mantidos em sala climatizada com temperatura de 25 ㄷ․ Avaliou-se a redução de massa, cor, potencial hidrogeniônico (pH), sólidos solúveis totais (SST), acidez total titulável (ATT), relação sólidos solúveis totais e acidez total titulável (SST/ATT), índice de maturação e incidência de patógenos. Utilizou-se o delineamento inteiramente casualizado, com quarenta e oito parcelas, totalizando 192 frutos. Foram realizadas análises físicoquímicas em três períodos, sendo uma avaliação anterior à incubação e duas após. As análises físico-químicas após a incubação foram realizadas ao 3ำ e 70 dias de armazenamento. As avaliações de incidência de patógenos e maturação foram realizadas diariamente. Para os parâmetros de ATT, SST, pH e SST/ATT não houve alteração decorrente da aplicação dos óleos essenciais, assemelhando-se aos resultados encontrados na literatura. Os tratamentos com óleos essenciais não apresentaram eficiência no controle de patógenos pós-colheita, porém observa-se que óleo de alecrim controlou a maturação dos frutos em pós-colheita.

Palavras-chave: Óleos Essenciais; Solanum Lycopersicum; Características Físico-Químicas.

\section{Alternative control of the postharvest rot in tomato}

\begin{abstract}
Brazil is a major tomato producer, but most production destined for domestic consumption because it does not fit to international standards. In this paper the effect of essential oils on physicochemical parameters and in control of postharvest pathogens in tomato fruits were investigated. The treatments evaluated were Cantus ${ }^{\circledR}$ (positive control), distilled water (negative control); essential oils to $1 \%$ of rosemary (Rosmarinus officinalis), Cinnamon (Cinnamomum zeylanicum), Clove (Caryophillus aromaticus) and Copaíba (Copaifera sp.). ${ }^{\otimes}$ (positive control); via immersion of the fruit, followed by incubation in wet room / 24 hours. The fruits were immersed in the treatments, incubated ones in a humid chamber for 24 hours and kept in an air-conditioned room with a temperature of $25 \circ \mathrm{C}$. It were evaluated mass reduction, color hydrogen potential (pH), total soluble solids (TSS), total titratable acidity (TTA), total soluble solids and titratable acidity (TSS / TTA), maturation index and incidence of pathogens. The completely randomized design with forty-eight installments, totaling 192 fruits. Physicochemical analyzes in the three periods, one evaluation before incubation and two after. The physicochemical analysis after incubation were performed at 3 and 7 days of storage. Evaluations of incidence of pathogens and maturation were performed daily. For ATT parameters, TSS, pH and TSS / TTA no change resulting from the application of essential oils, resembling the results found in the literature. Treatments with essential oils did not show efficiency in the control of post-harvest pathogens, but it was noted that the rosemary oil controlled the ripening of fruits in postharvest.
\end{abstract}

Keywords: Essential Oils; Solanum Lycopersicum; Physicochemical Characteristics.

Topic: Química Agrícola e Ambiental

Reviewed anonymously in the process of blind peer

Roberta Flávia Cipriano Machado

Universidade do Estado de Mato Grosso, Brasil

http://lattes.cnpq.br/9656378069807653

robertafcmachado@gmail.com

\section{Solange Maria Bonaldo}

Universidade Federal de Mato Grosso, Brasil

http://lattes.cnpq.br/3703629752105309

sbonaldo@ufm.br

\section{Carmen Wobeto}

Universidade Federal de Mato Grosso, Brasil

http://lattes.cnpq.br/7629112688399234

carmenwobeto2014@gmail.com

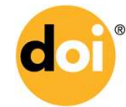

DOI: 10.6008/SPC2179-6858.2017.001.0009
Received: 18/04/2016

Approved: 20/05/2016

\begin{abstract}
Carolina de Faria Cabral Paes Pereira e Barros Universidade do Estado de Mato Grosso, Brasi http://lattes.cnpq.br/0295705255313092 carolinna.ef@gmail.com
\end{abstract}

Rozineide Pereira Alves de França

Universidade do Estado de Mato Grosso, Brasil http://lattes.cnpq.br/9528218272560564 rose-eafc@hotmail.com

Referencing this:

MACHADO, R. F. C.; BONALDO, S. M.; WOBERTO, C.; BARROS, C. F. C. P. P.; FRANÇA, R. P. A.. Controle alternativo de podridões pós-colheita em tomate. Revista Ibero-Americana de Ciências Ambientais, v.8, n.1, p.99-118, 2017. DOI: http://doi.org/10.6008/SPC21796858.2017.001.0009 


\section{INTRODUÇÃO}

O tomateiro (Solanum lycopersicum) é uma planta originária dos países andinos, pertencente à família das Solanaceas, sendo uma das hortaliças mais cultivadas em todo o mundo (FILGUEIRA, 2008). Tratase de uma planta perene, no entanto, é cultivada como herbácea de ciclo anual e porte arbustivo. Pode ser cultivado em dois tipos de segmentos produtivos, um destinado ao mercado para consumo in natura e outro para processamento industrial (FILGUEIRA, 2008).

A cultura apresenta ciclo relativamente curto, em média de 75 a 80 dias inicia-se a colheita e com possibilidade de alto rendimento, trata-se de uma cultura que tem ótimas perspectivas econômicas. Em 2014 o Brasil produziu cerca 4 milhões de toneladas de frutos de tomateiro, aparecendo como nono maior produtor no ranking mundial (AGRIANUAL, 2015).

Esse crescimento da produção de tomate é decorrente de seu elevado valor nutricional e aumento da população. Entre as propriedades funcionais destacadas no fruto do tomate encontram-se flavonoides, fitoalexinas, pigmentos como carotenoides e antocianinas. Apresenta ainda em sua composição baixos teores de gorduras e calorias $(0,2 \mathrm{~g}$ de gordura em $100 \mathrm{~g}$ de tomate e 15 calorias), altos teores para fibras $(1,5 \mathrm{~g})$, vitaminas (A e C), minerais (fósforo, potássio, cálcio, sódio e ferro), $\beta$-caroteno, licopeno (30mg de licopeno/kg) e outros antioxidantes (MANGELS et al., 1993).

Decorrente do aumento exponencialmente da agricultura e sua potencialidade de produção, há também um aumento significativo no uso de agroquímicos para o controle de pragas e doenças. O controle químico convencional defronta com o surgimento de patógenos resistentes às moléculas químicas utilizadas (PASCHOLATI, 1998). Sobretudo, a resistência dos patógenos aos fungicidas tem conferido certa ineficiência no controle, incentivando a crescente busca por métodos alternativos de controle e de baixo impacto socioeconômico e ambiental.

O uso de extratos brutos aquosos e óleos essenciais de diversas plantas têm sido utilizado e difundido por apresentarem potencial elevado no controle de fitopatógenos, por sua ação fungicida inibindo crescimento micelial e germinação de esporos de fungos fitopatogênicos (ITAKO et al., 2008; SCHWANESTRADA et al., 2008, LIMA et al., 2014) podendo apresentar também efeitos voláteis sobre fitopatógenos (LORINI et al., 2016).

As perdas pós-colheita em produtos hortifrutícolas decorrem de inúmeros fatores, tais como: perdas fisiológicas, microbiológicas, físicas e mecânicas. No entanto, as perdas ocasionadas por microrganismos patogênicos são as causas mais importantes nesta fase (CHITARRA e CHITARRA, 1990). Tais perdas podem ser quantitativas, quando se tem grande parte dos tecidos deteriorados, ou qualitativas, onde as perdas são pequenas, contudo, o aspecto visual do produto fica bastante comprometido, tornando-o não comercial ou reduzindo o seu valor econômico (GOMES, 1996; CHITARRA e CHITARRA, 1990).

Com base neste cenário, o grande desafio é encontrar medidas alternativas para o controle de doenças, que sejam viáveis, tanto no aspecto econômico quanto ambiental. Assim, objetivou-se, com esse trabalho, determinar os possíveis efeitos de diferentes óleos essenciais no controle de podridões pós- 
colheita, bem como nos atributos físico-químicos de frutos de tomateiro.

\section{REVISÃO TEÓRICA}

\section{Aspectos Gerais Sobre a Cultura do Tomate (Solanum lycopersicum)}

O tomateiro é uma planta autógama, eudicotiledônea, pertencente à família das Solanáceas, da qual também faz parte a berinjela, a batata, a pimenta, o pimentão, entre outras hortaliças. Suas folhas são alternadas e cobertas com tricomas glandulares, que ao serem esmagadas, emitem um cheiro característico das Solanáceas. As flores do tomateiro são pequenas, de cores amareladas, formato de cachos e são hermafroditas. A polinização é por autofecundação, pois a frequência de cruzamentos é muito baixa (RICK e BUTLER, 1996).

Conforme Filgueira (2000) o tomateiro é uma solanácea herbácea, de caule flexível, piloso, cuja arquitetura natural lembra uma moita, apresentando ramificação lateral abundante. Podendo ter essa arquitetura modificada pela poda, condicionando o tipo de cultura, de indústria no cultivo rasteiro ou para consumo fresco, no cultivo envarado ou estaqueado.

O fruto do tomateiro é do tipo baga, com tamanhos e formas variáveis, constitui-se de película, polpa, placenta e sementes. Internamente, é dividido em lóculos onde as sementes encontram-se imersas na mucilagem placentária e, dependendo da cultivar, os frutos podem ser biloculares, triloculares, tetraloculares ou pluriloculares (MELO, 1989).

Atualmente, consideram-se seis segmentos principais: santa cruz, salada ou saladete, caqui, italiano, cereja e penca (FERREIRA et al., 2004). A composição do fruto de tomateiro contem cerca de $93 \%$ a $95 \%$ de água. Nos 5\% a 7\% restantes, encontram-se compostos inorgânicos, ácidos orgânicos, açúcares, sólidos insolúveis em álcool e outros compostos (EMBRAPA HORTALIÇAS, 2003). O consumo pode ser feito tanto na forma in natura como processada na forma de molhos, secos, enlatados, entre outras (DUMAS et al., 2003).

A alta crescente de consumo do tomate tanto nas formas in natura, quanto na forma de produtos concentrados, registra-se uma expansão do cultivo do tomateiro favorecendo a venda do produto (CARVALHO e PAGLIUCA, 2007).

\section{Parâmetros de Qualidade}

Cor, firmeza dos frutos, perda de peso, pH, acidez titulável, teor de sólidos solúveis, nitratos e nitritos, contagem de microrganismos, presença de pesticidas, entre outros, são indicadores empregados para avaliar a qualidade de tomates no período pós-colheita (FERREIRA, 2004).

Encontradas na parede celular das células, as substâncias pécticas conferem firmeza da polpa e textura do fruto que é definida como o conjunto de propriedades do alimento, composto por características físicas perceptíveis pelo tato e que se relacionam com a deformação, desintegração e fluxo do alimento, sob a aplicação de uma força (ALMEIDA, 1995). O potássio (K) é um dos elementos de extrema importância para a cultura, pois sua deficiência está diretamente relacionada à firmeza de sua polpa e na formação de 
carotenoides, que incluem o licopeno, que é um dos mais importantes pigmentos contidos nos frutos do tomate (GIORDANO et al., 2000).

Na determinação da cor do tomate ao longo do tempo de maturação, têm-se três estágios de cromaticidade. Um estágio inicial, quando o tomate apresenta-se com menos croma, refere-se ao período entre o primeiro e o oitavo dia de maturação; um estágio intermediário, quando o tomate apresenta-se com croma um pouco mais elevado, espera-se que ocorra entre o oitavo e o décimo quinto dia de maturação; e o estágio final, quando o tomate revela o maior croma a partir do décimo quinto dia de maturação (ALMEIDA, 1995).

O teor de sólidos solúveis totais (SST) é medido por refratometria e usado como índices de açúcares totais em frutas (CECCHI, 1999) indicando o grau de amadurecimento. É constituído por compostos solúveis em água que representam os açúcares, ácidos, vitamina C e algumas pectinas (MOURA, SARGENT e OLIVEIRA, 1999; OLIVEIRA et al., 1999).

Quanto mais elevado for o teor de SST ( $\left.{ }^{\circ} \mathrm{Brix}\right)$ maior é o rendimento quando se trata de tomate industrial e menor gasto de energia no processo de concentração de polpa. Geralmente, os teores de SST aumentam com o amadurecimento dos frutos através do processo de biossíntese ou pela degradação de polissacarídeos (CHITARRA e CHITARRA, 1990).

Acidez titulável total (ATT) é um importante parâmetro na apreciação do estado de conservação de um produto alimentício. Geralmente o processo de decomposição do alimento, seja por hidrólise, oxidação ou fermentação, altera quase sempre a concentração de íons de hidrogênio (IAL, 1985), por consequência sua acidez. Em relação ao conteúdo de açúcar, a acidez titulável total (ATT) é útil na determinação da maturação da fruta (CECCHI, 1999).

Os compostos antioxidantes são capazes de inibir ou retardar a oxidação, quando presentes em baixas concentrações em relação ao substrato oxidável. Ao doar seus elétrons eles não se tornam radicais livres, pois são estáveis (HALL III e CUPPETT, 1997). Conforme Bianchi (1999), esses compostos interceptam os radicais livres gerados pelo metabolismo celular ou por fontes exógenas, impedindo o ataque sobre os lipídeos, os aminoácidos das proteínas, a dupla ligação dos ácidos graxos poli-insaturados e as bases do DNA, evitando a formação de lesões e perda da integridade celular.

Entre os compostos antioxidantes presentes nos vegetais, mais frequentemente encontrados e ativos são os compostos fenólicos, tais como os flavonoides, que possuem a capacidade de sequestrar os radicais livres (DECKER, 1997). Os carotenoides mais frequentemente encontrados nos alimentos de origem vegetal são o $\beta$-caroteno (cenoura; Daucus carota), licopeno (tomate; Lycopersicum esculentum), várias xantofilas (zeaxantina, luteína e outras estruturas oxigenadas do milho, Zea mays; da manga, Mangifera indica L.; do mamão, Carica papaya e da gema de ovo) e a bixina (aditivo culinário e corante dérmico usado por indígenas amazônicos; obtido do urucum, Bixa orellana) (RODRIGUEZ-AMAYA et al., 2008; DAMODARAN et al., 2008).

Segundo Rodriguez-Amaya (2008), os carotenoides se encontram naturalmente protegidos no tecido vegetal. O corte e a trituração das frutas e hortaliças acarretam a liberação de enzimas que catalisam a 
oxidação, bem como aumentam a exposição dos carotenoides ao oxigênio.

O licopeno, carotenoide frequentemente encontrado em tomate, tem sido destaque na saúde humana (KHACHIK et al., 2002), sendo a evidência científica mais forte em relação a sua atividade anticancerígena. A faixa de licopeno encontrada para frutos bem pigmentados, segundo Resende et al. (2004) varia entre 75 a $89 \mu \mathrm{g} / \mathrm{g}$ de fruto fresco.

\section{Doenças Pós-Colheita em Tomate}

As doenças pós-colheita em frutos são responsáveis por grandes perdas antes de chegar à mesa do consumidor, sendo em muitos casos superiores a 50\% (TAVARES, 2004). No varejo, os depósitos não oferecem condições satisfatórias e, normalmente os funcionários não estão treinados para praticar as formas corretas de manuseio, o que resulta em muitos casos em ferimentos e amassamentos. Os consumidores, por sua vez, manuseiam inadequadamente e excessivamente os produtos durante a escolha, contribuindo para a depreciação do fruto. Decorrente destes fatores, grande parte dos estoques de produtos hortícolas são diariamente destinados ao lixo (VILELA e MACEDO, 2000).

Os produtos hortícolas são susceptíveis ao ataque de vários patógenos após a colheita, mesmo quando o transporte e armazenamento são realizados de maneira adequada, verificando perdas de produção de até 10\% (GOMES et al., 2005). Entretanto, os prejuízos podem ser totais quando decorrentes de infeç̧ões muito severas ou dos danos provocados por armazenamento inadequado (ECKERT, 1991). Os fatores, hospedeiro, patógeno e ambiente, influenciam largamente o desenvolvimento de doenças pós-colheita (GOMES et al., 2005).

Os patógenos mais frequentemente encontrados em frutos de tomate na pós-colheita são: fungos: Botrytis cinerea, Alternaria solani, A. alternata, Rhizopus stolonifer, Geotrichum candidum e Colletotrichum spp.; bactérias: Erwinia spp. (LOPES e ÁVILA, 2005; ZAMBOLIM et al., 1997). Estes patógenos podem ser encontrados nos ambientes de seleção e embalagem, locais de transporte e armazenamento dos frutos (SILVEIRA et al., 2001).

A redução de doenças pós-colheita é um dos grandes desafios para minimizar perdas. Atualmente, este controle tem sido à base de fungicidas, e em menor escala, de tratamentos físicos associados ao controle químico. Porém, a crescente exigência por produtos vegetais livres de contaminação por microrganismos e resíduos químicos, restringe o uso de defensivos agrícolas em pós-colheita, acarretando um aumento no desenvolvimento de pesquisas que visem métodos alternativos químicos, físicos e biológicos (MARI e GUIZZARDI, 1998).

Entre as estratégias utilizadas para o controle de doenças pós-colheita tem-se o controle físico, envolvendo condições de saneamento, controle de temperatura, umidade e modificação de atmosfera (KLUGE et al., 2002; CHITARRA e CHITARRA, 1990), os controles alternativo e biológico e, o controle químico, com o emprego de produtos químicos.

A refrigeração é uma das estratégias indicadas para prolongar a vida de pós-colheita de frutas, suprimindo o desenvolvimento de podridões. $O$ efeito inibidor da temperatura sobre os patógenos é muito 
variável, sendo que a maioria deles apresenta melhor desenvolvimento entre 20 e 25 ㄷ. Os patógenos, Colletotrichum spp. e Aspergillus spp. têm seu desenvolvimento inibido em condições de temperaturas inferiores a $10 \stackrel{\circ}{ } \mathrm{C}$, mas Botrytis cinerea se desenvolve, ainda que lentamente, a 0 으 (BENATO et al., 2001), fato que ressalta a necessidade de estudos que prolonguem a vida de prateleira dos produtos, além do controle de patógenos nesta fase e de forma que não produza danos ao ambiente.

O Brasil é um dos países mais ricos do mundo em espécies vegetais, com grande biodiversidade de substâncias que atuam sobre doenças e pragas das culturas e que devem ser estudadas e utilizadas, com o intuito de minimizar os efeitos negativos do uso indiscriminado de defensivos e aumentar a produção de alimentos de alta qualidade, propiciando assim o desenvolvimento de uma agricultura alternativa e sustentável (BETTIOL, 1991).

Óleos essenciais (OEs) são produtos aromáticos de metabolismo secundário de plantas, normalmente produzidos por células secretoras ou grupos de células, sendo encontrados em diversas partes do vegetal, como folhas e talos. São concentrados em uma região do vegetal, como folhas, casca ou frutos, e frequentemente apresentam composição diferente (CONNER, 1993). O uso de óleos essenciais como ingredientes funcionais em formulações alimentícias, cosméticas ou ainda em formulações sanitizantes, tem despertado grande interesse neste setor industrial devido à grande aceitação dos consumidores por produtos naturais, bem como pelos danos à saúde propiciados pelos aditivos sintéticos (SCHERER et al., 2009).

Há inúmeros relatos sobre atividade biológica de extratos vegetais, como ação antifúngica (KORUKLUOGLU et al., 2008), ação antibacteriana (AL-TURKI et al., 2008), atividade antitumoral (KAILEH et al., 2007), ação anti-inflamatória e analgésica (DÍAZ-VICIEDO et al., 2008) atividade antioxidante (STARZYNISKA-JANISZEWSKA et al., 2008), dentre outras.

\section{Óleos Essenciais no Manejo de Doenças}

Os óleos essenciais (OEs) são compostos obtidos de partes de plantas através de destilação por arraste de vapor d'água, segundo definição da ISO (International Standard Organization). Possuem em sua composição hidrocarbonetos terpênicos, álcoois simples e terpênicos, aldeídos, cetonas, fenóis, ésteres, óxidos, peróxidos, ácidos orgânicos, lactonas, cumarinas e compostos de enxofre, que são complexos e variáveis (SIMÕES et al., 1999; SIMÕES e SPITZER, 2000 e DORAN e BROPHY, 1990).

Apresentam características peculiares odoríferas, lipofílicas, líquidas, e voláteis, conhecidos também como óleos voláteis, óleos etéreos ou essências, ocorrendo sempre um composto majoritário, e outros em menores quantidades (SIMÕES et al., 1999; SIMÕES e SPITZER, 2000). O uso indiscriminado e incorreto de defensivos agrícolas nos ambientes rural e urbano vem causando prejuízos aos ecossistemas, e tem motivado o desenvolvimento de métodos e produtos alternativos no controle de doenças de plantas (FERNANDES, 2000, CARVALHO et al., 2008; CARLOS et al., 2010, MATIELLO et al., 2016). Os óleos essenciais apresentam, atualmente, maior potencial para o desenvolvimento de produtos para controlar doenças em plantas (FAWZI et al., 2009; KNAAK e FIUZA, 2010; NERIO et al., 2010). 


\section{Alecrim (Rosmarinus officinalis)}

O alecrim (Rosmarinus officinalis L.), pertencente à família Lamiaceae (Labiatae), tem sua origem no Sul da Europa e Norte da África (MARTINS et al., 1998). De acordo com relatos encontrados na literatura, esta planta pode apresentar propriedades estomacais, estimulantes, antiespasmódica, emenagogas e cicatrizantes (MAY et al., 2010).

May et al. (2010) define esta planta como um subarbusto muito ramificado, sempre verde, com hastes lenhosas, folhas pequenas, sésseis, finas, opostas e lanceoladas, de sabor picante. A parte inferior das folhas é de cor verde-acinzentada, enquanto a superior é quase prateada. A planta possui aroma forte e agradável. Utilizada com fins culinários, medicinais e aromáticos, sendo o óleo essencial utilizado em cosméticos e perfumaria (MARTINS et al., 2000).

O óleo essencial de alecrim é muito utilizado nas indústrias cosméticas, de higiene e perfumaria na fabricação de sabonetes, shampoos, desodorantes, colônias e desinfetantes (ROBBINS e GREENHALGH, 1979). Além disso, o extrato alcoólico dessa planta tem uso como antioxidante na indústria alimentícia (ZEGARSKA et al., 1996). O extrato de alecrim tem recebido atenção especial nos últimos anos devido as propriedades antioxidantes que possui, reconhecidas desde a Antiguidade (PORTE e GODOY, 2001).

\section{Canela (Cinnamomum zeylanicum)}

A espécie Cinnamomum zeylanicum (sin. C. verum) conhecida como canela-da-índia, pertence à família Lauraceae e é originária do continente asiático (LIMA et al., 2005). O óleo essencial da canela é de alta qualidade e valor agregado. O rendimento de óleo da casca está em torno de $2 \%$, e das folhas $1 \%$. A composição do óleo essencial é muito variável, de 60 a 90\% de aldeído cinâmico e 10\% de eugenol na casca e 10\% de aldeído cinâmico e 60 a 95\% de eugenol nas folhas (ALBUQUERQUE, 1989).

A casca e as folhas de $C$. zeylanicum são geralmente usadas na perfumaria, fabricação de bebidas e culinária, devido as suas propriedades aromáticas e condimentares, e seus óleos essenciais são utilizados como agentes aromatizantes de alimentos industrializados e medicamentos (SILVA et al., 2012).

O óleo essencial dessa planta é um dos mais importantes no mercado mundial e apresenta grande diversidade na sua composição (LIMA et al., 2005). C. zeylanicum é muito utilizada na medicina popular por apresentar propriedades medicinais, tais como antiespasmódica, carminativa, estimulante, tônica, digestiva, adstringente, afrodisíaca, antisséptica, antioxidante, aperiente, aromática, hipertensora, sedativa e vaso dilatadora (SIMIC et al., 2004; LIMA et al., 2005; SILVA et al., 2012). Além de apresentar atividade antibacteriana e antifúngica (PAWAR e THAKER, 2006; HILI et al., 1997).

\section{Cravo-da-Índia (Caryophillus aromaticus)}

É uma planta amplamente utilizada para as mais diversas aplicações, como, por exemplo, anestesia para peixes durante o transporte ou para minimizar o estresse antes do abate (ROUBACH et al., 2005), ou ainda como anestésico tópico (ALQAREER al., 2006), além de ser muito utilizado na culinária. 
Relatos atribuem atividades biológicas ao óleo de cravo-da-índia na literatura atual, tais como antimicrobiana (VIUDA-MARTOS et al., 2007), antioxidante (SCHERER et al., 2009) e anestésica (SEOL et al., 2007). A composição volátil do óleo essencial de cravo-da-índia apresenta três compostos considerados majoritários, destacando-se o eugenol, com $83,75 \%$ da área total, seguido pelo $\beta$-cariofileno, com $10,98 \%$, e com 1,26\%, o $\alpha$-humuleno, além de outros compostos detectados em quantidades diminutas (SCHERER, et al., 2009).

\section{Copaíba (Copaifera sp.)}

A Copaifera L. é representante da família Leguminosae. Os indígenas denominaram o "produto milagroso", extraído do caule da árvore, como "copahu" ou "copaiva", proveniente de "kupa' iwa" da língua tupi, que quer dizer "planta da qual se extrai um óleo com propriedades medicinais" (FERREIRA, 1988; CUNHA, 1999; MARTINS-DA-SILVA, 2006). Provavelmente, a região Amazônica é a principal fornecedora deste óleo resina utilizado no mercado brasileiro e no mundo (CASCON e GILBERT, 2000).

A importância das árvores de copaíba (Copaifera spp.) deve-se principalmente à produção de óleoresina, utilizado pelas populações tradicionais e indústrias farmacêuticas através do seu uso "in natura" ou destilado, ou como componente na preparação de uma variedade de produtos terapêuticos e cosméticos, como xaropes, pomadas, cápsulas, óvulos vaginais, cremes, sabonetes, xampus, detergentes e loções; possui ainda potencial para uso industrial em tintas, vernizes e como fixador de fragrância de perfumes (RIGAMONTE-AZEVEDO et al., 2006).

O óleo de copaíba é constituído de dois grupos de substâncias distintas, solúveis entre si, sendo um constituído de substâncias voláteis, correspondendo a cerca de $90 \%$ de massa do óleo resina e outro grupo constituído de substâncias não voláteis, resinosa de cor caramelo que começa a ser decomposta à temperatura próxima de 300 드, e que corresponde a 10\% da massa total do óleo resina (VEIGA JUNIOR, 1997; CASCON e GILBERT, 2000).

O óleo essencial extraído das folhas da copaibeira possui composição semelhante à da parte volátil sesquiterpênica do óleo-resina, com substâncias como $\beta$-cariophileno, cadinol, Germacreno D e B e $\gamma$ cadineno (SILVA et al., 2006).

\section{METODOLOGIA}

A etapa experimental deste trabalho foi conduzida nos laboratórios de Tecnologia de Produção de Alimentos e Microbiologia/Fitopatologia, da Universidade Federal de Mato Grosso, Campus Sinop, no período de 01 de maio a 03 de junho de 2014. Os frutos foram obtidos de um produtor local da cultivar Viradoro (grupo Santa Cruz) e encaminhados ao laboratório, onde se realizou a sanitização em solução de hipoclorito de sódio na concentração de 1000 ppm por 10 minutos.

Em seguida os frutos foram secos com auxílio de papel toalha. Posteriormente foi realizada a avaliação física de pesagem (g), em todos os frutos de cada tratamento. Após a determinação do peso, os frutos foram submetidos à imersão nos tratamentos (Tabela 1), com Tween 80 a 1\%, por dois minutos. 0 
Tween 80 é um surfactante não iônico e emulsionante derivado do sorbitol o qual é obtido de diversos tipos de frutas, utilizado como agente dispersante para misturar água e solubilizar fragrâncias e óleos essenciais (GENNARO, 1995).

Tabela 1: Tratamentos empregados para controle de podridão pós-colheita em tomateiro cultivar Viradoro (Grupo Santa Cruz).

\begin{tabular}{cc}
\hline Tratamentos & Descrição \\
\hline T1 & Água destilada \\
T2 & Óleo essencial de Canela (Cinnamomum zeylanicum) \\
T3 & Óleo essencial de Cravo-da-Índia (Syzygium aromaticum) \\
T4 & Óleo essencial de Copaíba (Copaifera sp.) \\
T5 & Óleo essencial de Alecrim (Rosmarinus officinalis) \\
T6 & Fungicida Boscalida (2-Chloro-N-(4'-chlorobiphenyl-2-yl)nicotinamide) \\
\hline
\end{tabular}

Em todos os tratamentos foi utilizado Tween 80 a 1\%; Os tratamentos T2, T3, T4 e T5 foram empregados em solução a 2,0\% (v/v) dos óleos essenciais. O tratamento T6 foi empregado na concentração de 0,075 g/L.

Após terem sido tratados, os frutos seguiram para incubação por $24 \mathrm{~h}$ em câmara úmida e foram acondicionados em bandejas de isopor envoltas em sacos plásticos. Os frutos permaneceram em fotoperíodo com monitoramento da temperatura $(25 \pm 2$ 으) e da umidade relativa ( $85 \pm 5 \%$ U.R.), por um período de sete dias. As variáveis abaixo foram avaliadas diariamente pelo período de sete dias no laboratório de Microbiologia/Fitopatologia:

a) Incidência de patógenos: onde foi calculada a porcentagem de frutos com sintomas e sinais (AMORIM, 1995), a partir do número de frutos infectados pelos patógenos em cada tratamento, pela fórmula:

$\%$ Incidência = (№ de frutos infectados/№ total de frutos) $\times 100$

A partir dos dados obtidos calculou-se a área abaixo da curva de progresso da incidência da doença (AACPD), conforme a fórmula:

$$
A A C P D=\sum_{i=1}^{n}\left(\frac{\left(y_{i}+y_{i+1}\right)}{2}\right)\left(t_{i+1}-t_{i}\right)
$$

Onde, $n$ é o número de avaliações, $x$ a proporção de incidência e $\left(t_{i+1}-t_{i}\right) \circ$ intervalo de avaliações consecutivas (CAMPBELL e MADDEN, 1990).

b) Maturação: foi utilizada a escala diagramática proposta por Abreu e Fernandes (2001) (Figura 1). As variáveis listadas a seguir, foram analisadas no Laboratório de Tecnologia e Produção de Alimentos, da Universidade Federal de Mato Grosso, Campus Sinop, no período de 01 de maio a 03 de junho de 2014. As análises foram realizadas anteriormente à incubação e após a incubação ao terceiro e ao sétimo dia de avaliação.

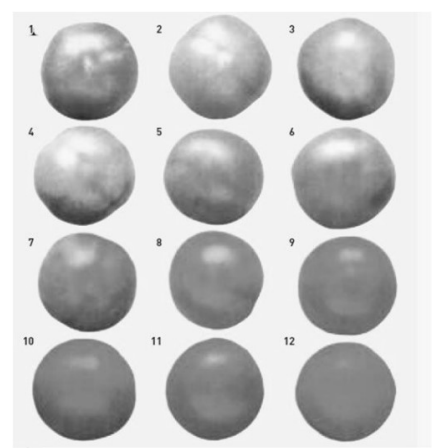

Figura 1: Escala de cor de 1 a 12 para a classificação do grau de maturação em tomate. Fonte: ABREU et al. (2001). 
c) Sólidos Solúveis Totais (SST): o teor de sólidos solúveis foi determinado através da leitura em um refratômetro portátil em bancada, utilizando-se $1 \mathrm{~g}$ do suco, apresentando o resultado em graus Brix (으ix). d) Potencial Hidrogeniônico $(\mathrm{pH})$ : o pH foi determinado através do método potenciométrico, calibrando-se o peagâmetro modelo MPA-210 com soluções tampão de pH 4,0 e 7,0, de acordo com as instruções do manual do fabricante.

e) Acidez Total Titulável (ATT): a Acidez Total Titulável (ATT) foi determinada através da titulação com $\mathrm{NaOH}$ $(0,1 \mathrm{~N})$ até atingir o ponto de virada. O resultado obtido foi expresso em $\mathrm{mg}$ de ácido cítrico/100ml de suco (mg/100g).

f) Relação SST/ATT: foi obtida a partir dos resultados de SST e ATT.

$\mathrm{Na}$ análise estatística das variáveis físico-químicas empregou-se o delineamento experimental inteiramente casualizado (DIC), através do esquema fatorial 6x2 (seis tratamentos por dois dias de avaliações em função do armazenamento), sendo realizadas no 3 o e 7을 dias. O ensaio foi montado com quarenta e oito parcelas, sendo cada unidade experimental composta por quatro frutos, totalizando 192 frutos. Os resultados das análises físico-químicas foram submetidos à análise de variância e as médias de cada variável, comparadas pelo teste Tukey a 5\% de probabilidade, pelo software SISVAR (FERREIRA, 2011).

Para avaliações de maturação e AACPD utilizou-se o delineamento experimental inteiramente casualizado, com oito repetições, com quatro frutos cada, sendo 32 frutos por tratamento. Os resultados foram comparados pelo teste Scott-Knott a $5 \%$ de probabilidade. O programa SASM-Agri (CANTERI et al., 2001) foi utilizado para a execução da análise de variância e aplicação do teste de média.

\section{RESULTADOS}

\section{Componentes Físico-Químicos}

Na Tabela 1 são apresentados os resultados das avaliações químicas e físicas (ATT, SST, pH, SST/ATT, peso (g) e cor com as variáveis $L^{*}, a^{*}$ e b*) da cultivar Viradoro no ponto de colheita, ou seja, no período anterior a imersão nos tratamentos, a fim de usá-los como base para compará-los com os resultados após os tratamentos e também com outros autores, durante os diferentes períodos de armazenamento (três e sete dias), para determinação da eficiência dos tratamentos com óleos essenciais.

Tabela 2: Valores médios \pm desvio padrão dos parâmetros de Acidez Total Titulável (ATT), Sólidos Solúveis Totais (SST), Potencial Hidrogeniônico $(\mathrm{pH})$, relação Sólidos Sóluveis Totais e Acidez Total Titulável (SST/ATT), Peso (g) e L* (luminosidade), a*(transição da cor verde para vermelha), b*(transição da cor azul para amarela) dos frutos de tomate cv. Viradoro no estágio verde maduro.

\begin{tabular}{cccccccc}
\hline \multicolumn{1}{c}{ Parâmetros } \\
\hline ATT & SST & pH & SST/ATT & Peso (g) & L & a & b \\
\hline $0,69 \pm 0,11$ & $4,35 \pm 0,46$ & $4,3 \pm 0,14$ & $6,39 \pm 0,66$ & $126,05 \pm 2,02$ & $48,52 \pm 0,55$ & $15,85 \pm 1,22$ & $18,38 \pm 0,95$ \\
\hline
\end{tabular}

Na Tabela 3, encontram-se os valores referentes aos teores médios encontrados para os parâmetros químicos de ATT, SST, pH e a relação SST/ATT dos frutos de tomateiro cv. Viradoro, nas análises realizadas ao terceiro e sétimo dia de avaliação. Os tratamentos avaliados não diferiram estatisticamente entre si, nos dois períodos de armazenamento, para todas as características avaliadas, porém, nota-se redução nos 
valores médios para o parâmetro ATT quando comparados com o valor médio encontrado em prétratamento (anterior ao período de imersão dos frutos).

O tratamento T1 para as características ATT, pH e SST/ATT diferiu estatisticamente em relação aos dois períodos de armazenamento, visto que houve incremento nos valores destas características. Resultados semelhantes foram encontrados para o T2 em relação aos valores de SST, T3 para pH e T6 para SST e pH. Os tratamentos T4 e T5 não diferiram estatisticamente em relação aos dias de armazenamento para todas as características.

Tabela 3: Teores médios de Acidez Total Titulável (ATT), Sólidos Solúveis Totais (SST), pH e SST/ATT de tomate, cultivar Viradoro, submetidos aos tratamentos de controle de patógenos pós-colheita, após o terceiro e sétimo dia de armazenamento.

\begin{tabular}{|c|c|c|c|c|c|c|c|c|}
\hline \multirow{2}{*}{ Tratamentos } & \multicolumn{2}{|c|}{ ATT } & \multicolumn{2}{|c|}{ SST } & \multicolumn{2}{|c|}{$\mathrm{pH}$} & \multicolumn{2}{|c|}{ SST/ATT } \\
\hline & 3ㅇdia & 7ㅇdia & 3ㅇia & 70-dia & 3ㅇia & 70dia & 3ㅇdia & 7ㅇdia \\
\hline $\mathrm{T} 1$ & $0,49 a B$ & $0,36 a A$ & $4,69 a A$ & $4,91 \mathrm{aA}$ & $4,50 a A$ & $4,72 \mathrm{aB}$ & $10,11 \mathrm{aA}$ & $15,11 \mathrm{aB}$ \\
\hline $\mathrm{T} 2$ & $0,47 a A$ & $0,47 a A$ & $4,88 \mathrm{aA}$ & $5,54 a B$ & $4,63 a A$ & $4,54 a A$ & $11,05 a A$ & $12,25 \mathrm{aA}$ \\
\hline T3 & $0,47 a A$ & $0,46 a A$ & $5,04 a A$ & $5,24 a A$ & $4,55 a A$ & $4,58 \mathrm{aB}$ & $10,79 a A$ & $11,79 a A$ \\
\hline $\mathrm{T} 4$ & $0,46 a A$ & $0,50 \mathrm{aA}$ & $4,80 \mathrm{aA}$ & $5,13 a A$ & $4,67 a A$ & $4,50 a A$ & $10,95 a A$ & $11,08 \mathrm{aA}$ \\
\hline T5 & $0,47 a A$ & $0,46 a A$ & $4,84 a A$ & $4,93 a A$ & $4,60 a A$ & $4,62 \mathrm{aA}$ & $11,31 \mathrm{aA}$ & $11,01 \mathrm{aA}$ \\
\hline T6 & $0,42 a A$ & $0,46 a A$ & $4,45 a A$ & $5,15 a B$ & $4,52 \mathrm{aA}$ & $4,71 \mathrm{aB}$ & $10,78 a A$ & $12,60 \mathrm{aA}$ \\
\hline
\end{tabular}

T1: água destilada; T2: óleo essencial de Canela; T3: óleo de Cravo-da-Índia; T4: óleo de Copaíba; T5: óleo de Alecrim; T6: fungicida Boscalida. Em todos os tratamentos foram adicionados Tween 80 a 1\%. Em cada parâmetro avaliado, valores com letras minúsculas iguais na coluna e letras maiúsculas iguais nas linhas, não diferem pelo teste de Tukey $(p \leq 0,05)$.

$\mathrm{Na}$ Tabela 4, encontram-se os valores médios dos componentes físicos: Peso (g), Luminosidade (L) e transição de cores ( $a^{*}$ e $\left.b^{*}\right)$. Os valores médios para o parâmetro peso demonstram que os tratamentos diferiram estatisticamente entre si. Observou-se que o tratamento T3 apresentou redução no peso quando comparados aos resultados médios observados em pré-tratamento e bem como, em relação às testemunhas.

Tabela 4: Teores médios de Peso (g) e L* (luminosidade), a*(transição da cor verde para vermelha), b*(transição da cor azul para amarela), de frutos cultivar Viradoro, submetidos aos tratamentos de controle de patógenos pós-colheita no sétimo dia de avalição (último dia).

\begin{tabular}{ccccc}
\hline Tratamentos & Peso $(\mathrm{g})$ & $\mathrm{L}$ & $\mathrm{a}$ & $\mathrm{b}$ \\
\hline T1 & $114,20 \mathrm{f}$ & $41,12 \mathrm{a}$ & $20,79 \mathrm{bc}$ & $22,04 \mathrm{ab}$ \\
T2 & $98,33 \mathrm{~b}$ & $41,37 \mathrm{a}$ & $9,66 \mathrm{a}$ & $21,19 \mathrm{ab}$ \\
T3 & $99,20 \mathrm{c}$ & $43,59 \mathrm{a}$ & $13,26 \mathrm{ab}$ & $16,72 \mathrm{a}$ \\
T4 & $75,72 \mathrm{a}$ & $38,11 \mathrm{a}$ & $23,20 \mathrm{c}$ & $24,75 \mathrm{~b}$ \\
T5 & $113,54 \mathrm{e}$ & $42,00 \mathrm{a}$ & $17,37 \mathrm{bc}$ & $24,73 \mathrm{~b}$ \\
T6 & $100,35 \mathrm{~d}$ & $41,88 \mathrm{a}$ & $22,77 \mathrm{c}$ & $20,38 \mathrm{ab}$ \\
\hline
\end{tabular}

T1: água destilada; T2: óleo essencial de Canela; T3: óleo de Cravo-da-Índia; T4: óleo de Copaíba; T5: óleo de Alecrim; T6: fungicida Boscalida. Em todos os tratamentos foram adicionados Tween 80 a 1\%. Em cada parâmetro avaliado, valores com letras minúsculas iguais na coluna e letras maiúsculas iguais nas linhas, não diferem pelo teste de Tukey ( $p$ $\leq 0,05)$.

Em relação ao parâmetro luminosidade, não houve diferença estatística entre os tratamentos, enquanto que para coloração ( $a^{*}$ e b*) foi possível observar diferenças significativas entre as médias, entre as quais os tratamentos T1 e T2 apresentaram menores valores de transição da cor verde para vermelha (a*) e transição de cor azul para amarela ( $\left.b^{*}\right)$, o que indica que estes tratamentos interferem negativamente neste parâmetro, visto que os frutos com maiores valores para o parâmetro a*, são desejados pelo mercado, que é o fator que confere a coloração vermelha intensa do fruto. 


\section{Conservação Pós-Colheita}

A maturação dos frutos foi avaliada no primeiro, ou seja, 24 horas após a submissão dos frutos aos tratamentos e último dia de avaliações (Figura 2). Verificou-se que no primeiro dia de avaliação da maturação os tratamentos T1 e T4 diferiram significativamente dos demais, apresentando-se com maior grau de maturação.

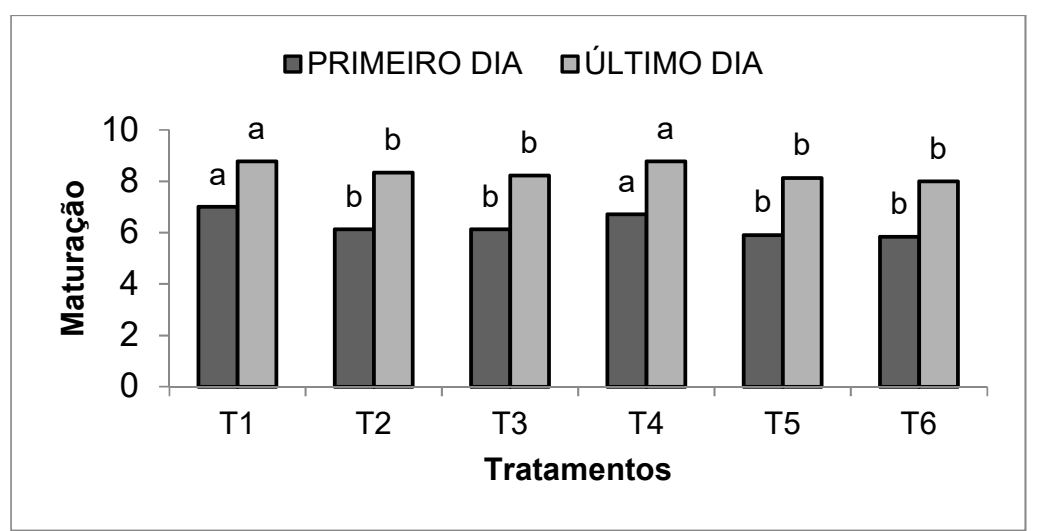

Figura 2: Maturação dos frutos de tomate no primeiro e último dia do ensaio, após tratamento com os óleos essenciais, sendo: T1 - Água destilada (testemunha negativa); T2 - Alecrim; T3 - Canela; T4 - Cravo; T5 - Copaíba e T6 - fungicida Cantus ${ }^{\circledR}$ (testemunha positiva), por imersão, incubados em fotoperíodo e $25^{\circ} \mathrm{C}$. Letras iguais para cada dia de avaliação significa que os tratamentos não diferiram entre si pelo teste Scott-Knott $(p \leq 0,05)$.

A maturação dos frutos de tomateiro foi determinada ao longo de seis avaliações, visto que a primeira avaliação foi realizada 24 horas após imersão dos frutos nos tratamentos (Figura 3). 0 comportamento observado para a maturação de frutos ocorreu de forma esperada, visto que houve um incremento no grau de maturação no decorrer do período de avaliação. Nota-se que os tratamentos apresentaram comportamento semelhante, apresentando picos no grau de maturação do segundo para o terceiro dia e do quinto para o sexto dia. Os tratamentos T1 e T4 apresentaram os maiores valores, enquanto os tratamentos T6 e T5 os menores valores, corroborando com a Figura 2.

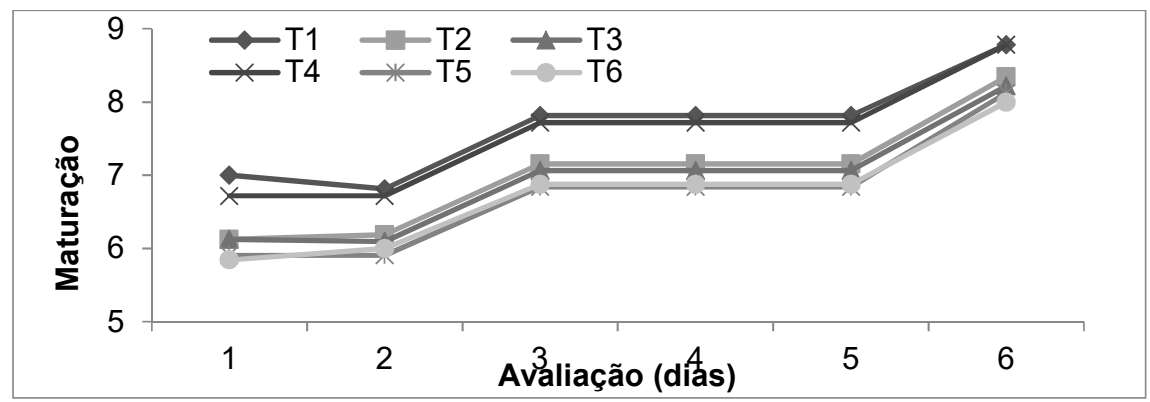

Figura 3: Maturação dos frutos de tomate do primeiro ao sexto dia de avaliação, após tratamento com os óleos essenciais, sendo: T1 - Água destilada (testemunha negativa); T2 - Alecrim; T3 - Canela; T4 - Cravo; T5 - Copaíba e T6 - fungicida Cantus ${ }^{\circledR}$ (testemunha positiva), por imersão, incubados em fotoperíodo e $25^{\circ} \mathrm{C}$. Letras iguais para cada dia de avaliação significa que os tratamentos não diferiram entre si pelo teste Scott-Knott $(p \leq 0,05)$.

\section{Área Abaixo da Curva de Progresso de Podridão Pós-Colheita}

Não houve eficiência dos tratamentos no controle de patógenos pós-colheita quando comparado às testemunhas (Figura 4). 


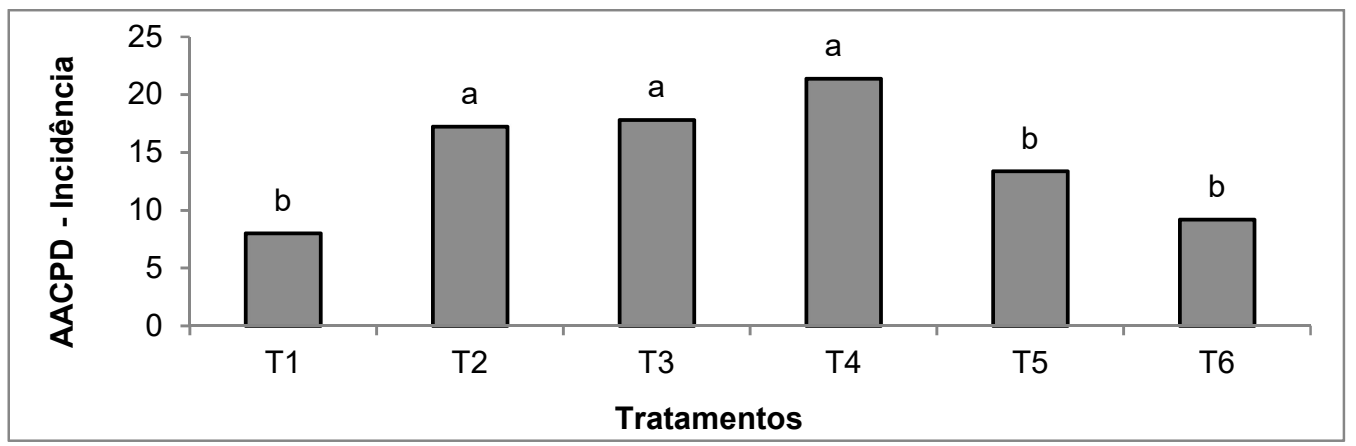

Figura 4: Área abaixo da curva de progresso de incidência (AACPD) de podridão em frutos de tomate da cultivar Viradoro, tratados por imersão com óleo essenciais de plantas medicinais de Alecrim, Canela, Cravo, espécie florestal Copaíba e fungicida Cantus ${ }^{\circledR}$. Letras iguais significam que não diferiram entre si pelo teste $\operatorname{Scott-Knott~}(p \leq 0,05)$.

Observa-se que os tratamentos T2, T3 e T4 diferiram estatisticamente entre os demais tratamentos, apresentando maior incidência de podridão nos frutos. Apesar do tratamento T4 não diferir estatisticamente dos tratamentos T2 e T3, nota-se maior AACPD neste tratamento.

\section{DISCUSSÃO}

\section{Componentes Físico-Químicos}

Observou-se que nos frutos no ponto de colheita do produtor e antes de submetê-los ao controle alternativo de fitopatógenos, os níveis de acidez foram superiores aos valores reportados por Carvalho e Tessarioli Neto (2005) (0,38\% a 0,41\%) e Shirahigeet al. (2010) (0,28\% a 0,41\%), que também avaliaram frutos dos segmentos Santa Cruz e Italiano, o que possivelmente pode ser decorrente das diferenças genéticas das cultivares.

A Acidez Total Titulável (ATT) é representada por teores de ácido cítrico que tem influência significativa sobre o sabor dos frutos, conforme Giordano et al. (2000). Os teores de ATT demonstraram que não houve diferença significativa entre os tratamentos em função do terceiro e sétimo dia de armazenamento (Tabela 3). Os teores de ATT assemelharam-se com os valores encontrados por Carvalho e Tessarioli Neto (2005). No entanto, o tratamento T1 (testemunha negativa) demonstrou um valor de 0,49 para o terceiro dia de avaliação e 0,36 no sétimo dia, havendo diferença significativa no decorrer do período de armazenamento. Essa redução é devido ao decréscimo no teor de ácidos orgânicos, que são utilizados como substratos no processo respiratório ou da sua transformação em açúcares (CHITARRA e CHITARRA, 1990). Logo, os tratamentos utilizados reduziram a degradação dos ácidos orgânicos.

O teor de Sólidos Solúveis Totais (SST) determinados em Brixo representa a porcentagem de sólidos que se encontram dissolvidos no alimento. Esses teores de SST podem aumentar de acordo com a evolução da maturação, devido aos processos de biossíntese ou através da degradação de polissacarídeos. Conforme Chitarra e Chitarra (1990) a avaliação do grau de doçura dos frutos são mais bem representados pelos teores de sólidos solúveis totais. Os valores médios de SST encontrados para os frutos no ponto de colheita do produtor, revelaram semelhança aos encontrados por Shirahige et al. (2010) (3,8 a 5,0 Brix). Teores de SST de nove cultivares diferentes produzidos na Espanha, revelaram valores entre 4,0 e 7,5 Brix, portanto, os teores deste trabalho apresentaram-se dentro da faixa citada (MARTINEZ-VALVERDE et al., 2002). Os teores 
de SST nos tomates submetidos aos tratamentos não apresentaram diferença significativa entre si em ambos os dias de avaliação (Tabela 3). Os valores médios de SST, portaram-se de forma semelhante aos valores encontrados por Shirahige et al. (2010). Em relação ao tempo de armazenagem, nota-se que os tratamentos T2 (canela) e T6 (testemunha positiva) apresentaram diferença significativa, havendo um incremento do teor de SST do terceiro para o sétimo dia de avaliação. Esse aumento significativo é devido à degradação de polissacarídeos, diretamente ligada ao processo de maturação, pois com a evolução da maturação tende acumular teores de SST.

Os valores médios de $\mathrm{pH}$ encontrados no presente trabalho para a cultivar Viradoro no ponto de colheita do produtor foram superiores aos valores encontrados por Shirahige et al. (2010) que variaram de 4,07 a 4,23; enquanto os valores de potencial hidrogênionico $(\mathrm{pH})$ para os frutos sob tratamento foram superiores aos encontrados por Shirahige et al. (2010) e Carvalho e Tessarioli Neto (2005). Os tratamentos não apresentaram diferença significativa, para ambos os dias de análises (Tabela 3). Os tratamentos T1 (testemunha negativa), T3 (cravo) e T6 (testemunha positiva) apresentaram acréscimo no valor de pH do terceiro para o sétimo dia, diferindo significativamente entre si.

Açúcares, ácidos e suas interações, possuem grande influência sobre o sabor do tomate. De posse dos valores de SST e ATT pode-se estabelecer a relação SST/ATT. Conforme Kader et al. (1978) relação SST/ATT acima de 10 caracterizam frutos de alta qualidade e sabor agradável, devido ao equilíbrio de ácidos e açúcares. Assim, relações inferiores a 10 estão diretamente relacionados ao sabor ácido, ou seja, os frutos serão considerados impróprios para o consumo in natura (ZAMBRANO et al., 1996). Os frutos no ponto de colheita do produtor exibiram valores para a relação SST/ATT abaixo de 10 , sendo considerados frutos impróprios para o consumo in natura no ponto de colheita em que foram analisados. $\mathrm{O}$ que atesta que os frutos estavam ainda no estágio verde maduro no ponto de colheita (KADER et al., 1978; ZAMBRANO et al., 1996). Deste modo, os valores encontrados para os frutos sob tratamento mostram que houve uma boa relação SST/ATT (Tabela 3). Nota-se que os óleos essenciais utilizados reduziram o processo de maturação dos frutos. Quanto aos tratamentos, não diferiram entre sim em ambos os dias de avaliação. No entanto, o tratamento T1 (testemunha negativa) apresentou um acréscimo na relação SST/ATT do terceiro dia para o sétimo dia, diferindo significativamente. Esse fato é explicado pela correlação com as demais variáveis analisadas, nas quais a testemunha apresentou acréscimo para pH e relação SST/ATT enquanto houve decréscimo no teor de $A T T$, demonstrando que esses resultados estão relacionados ao processo de maturação do fruto, o qual no decorrer do tempo de armazenamento tende a aumentar os processos respiratórios e aumentar a acidez do fruto e diluir os açúcares.

De modo geral, os tratamentos avaliados não diferiram estatisticamente entre si, nos dois períodos de armazenamento, para todas as características avaliadas. No entanto, foi possível observar que o T1 (testemunha negativa) para as características ATT, pH e SST/ATT diferiu estatisticamente em relação aos dois períodos de armazenamento, controversamente, os tratamentos T4 (copaíba) e T5 (alecrim) não diferiram estatisticamente entre os períodos de armazenamento, comprovando-se sua eficiência no controle da maturação, visto que o aumento destes parâmetros são proporcionais ao grau de maturação. 
Os valores médios dos componentes físicos: Peso (g), Luminosidade (L) e transição de cores (a* e b*), demonstram que os tratamentos diferiram estatisticamente entre si. Observou-se que o tratamento T3 apresentou redução no peso quando comparados aos resultados médios observados em pré-tratamento (anterior ao período de imersão dos frutos) e também em relação às testemunhas. Os demais valores obtidos embora diferentes estatisticamente encontram-se entre a faixa de peso encontrada por Da Graça (2013) que encontrou peso médio entre 80 a 200g, enquanto Figueiredo et al. (2012) para a mesma cultivar encontrou valores médios de $57,35 \mathrm{~g}$, deste modo os frutos deste trabalho apresentaram valores dentro do ideal. Observa-se (Tabela 4), que os tratamentos diferiram entre si, devido ao fato de que cada fruto é único e pode apresentar pequenas diferenças entre seu peso e demais características.

Entre os atributos que influenciam na aceitação do tomate pelo mercado consumidor estão a luminosidade e coloração. Os frutos em pré-tratamento, para o componente L* da variável cor encontrou-se o valor de 48,52, sendo considerado semelhante ao encontrado por Moura et al. (1999), que afirmaram que quando os frutos são submetidos a temperatura de $25 \circ \mathrm{C}$ os valores tendem a variar entre 43,22 a 44,26 , deste modo, assemelhando-se as resultados. No entanto, para a componente $a^{*}$ os valores apresentados foram de 4,84 a 15,85, diferindo dos encontrados por Borelli (2012) que apresentou valores entre -8,59 e 11,51; o que se deve ao fato das cultivares se portarem de formas distintas e que possivelmente os frutos do presente trabalho encontravam-se em pontos de maturação diferentes dos que foram utilizados no trabalho citado. De acordo com McGuire (1992) os valores do componente de cor b* podem variar de $-60 a+60$, sendo assim o valor encontrado para este componente no presente estudo portou-se de forma semelhante.

Para os frutos tratados, os valores de L* não demonstraram diferença significativa entre si (Tabela 4). Os resultados obtidos foram semelhantes aos encontrados no primeiro dia em que foram avaliados e aos resultados encontrados por Binoti et al. (2013) que variaram de 46,38 a 64,08 entre os estádios imaturo e de vez. O componente de cor a*, os valores obtidos, variaram de 9,66 a 23,20 (Tabela 4). Borelli (2012) encontrou valores entre -8,59 a -11,51, essa variação é devido a utilização de cultivares diferentes (Compak, T92 e Dominador) do grupo Salada e pontos de maturação diferentes, pois o ponto de colheita do produtor é bastante variável, haja visto que são características vistas de forma distinta para cada pessoa. Os tratamentos T4 (copaíba) e T6 (testemunha positiva) apresentaram os maiores valores de a*, diferindo significativamente dos demais tratamentos. Os tratamentos T1 (testemunha negativa) e T2 (canela) apresentaram os menores valores de a*, sendo indesejáveis para o mercado, visto que este parâmetro confere a coloração vermelho intenso. Deste modo, o melhor tratamento seriam os que apresentaram os maiores valores. Os valores do componente de cor b* apresentaram variação entre 16,72 a 24,75 (Tabela 4), que segundo McGuire (1992) pode variar de -60 a +60 .

\section{Conservação Pós-Colheita}

O grau de maturação dos frutos foi avaliado no primeiro dia, 24 horas após a submissão dos frutos aos tratamentos e último dia de avaliações. Verifica-se que no primeiro dia de avaliação a maturação da testemunha, e o tratamento com óleo essencial de copaíba diferiu significativamente dos demais (Figura 2). 
É provável que seja devido ao estágio de maturação que se encontravam, independente do seu tratamento. De forma semelhante, ocorreu no último dia de avaliação, ou seja, é possível que devido ao estágio de maturação que se encontravam desde o início do experimento apresentaram o mesmo comportamento ao longo das avaliações, no entanto, os tratamentos com óleo essencial (OE) de cravo, canela e alecrim e, o fungicida Boscalida, diferiram significativamente apresentando comportamento de controle de maturação, diferentemente da testemunha e do tratamento com OE de copaíba.

Ao longo do experimento, ou seja, durante as seis avaliações que foram realizadas diariamente, todos os tratamentos apresentaram comportamento semelhante ao longo do tempo (Figura 3). A testemunha e o tratamento com o óleo essencial de copaíba embora tenha demonstrado maiores valores do que os demais tratamentos não diferiram quanto ao comportamento ao longo das avaliações. Esse aumento em relação aos demais tratamentos é devido ao ponto de maturação que se encontrava diferente desde o início das avaliações, ou seja, desde o dia zero (período anterior aos tratamentos via imersão).

\section{Área Abaixo da Curva de Progresso de Podridão Pós-Colheita}

Observou-se que não houve eficiência em relação aos tratamentos empregados no controle da podridão pós-colheita, sendo os tratamentos T2, T3 e T4 os que apresentaram maiores valores para a área abaixo da curva de progresso da incidência de podridão (AACPD - incidência) (Figura 4), ou seja, os tratamentos estimularam a incidência de fitopatógenos quando comparados com a testemunha.

Apesar do tratamento T4 não diferir estatisticamente dos tratamentos T2 e T3, nota-se maior AACPD neste tratamento, corroborando com os resultados dos parâmetros físico-químicos, os quais também apresentaram diferenças significativas para este tratamento. A maior incidência de podridão de frutos nestes tratamentos e de acordo com os parâmetros químicos ATT, SST, pH e SST/ATT (Tabela 3), inferem que os tratamentos ao alterarem estes parâmetros, principalmente ATT e $\mathrm{pH}$, possibilitaram a proliferação de fitopatógenos nos frutos, fato que ocorre no processo de pós-colheita mas que foi acelerado pelo tratamento com óleos essenciais via imersão. Estes resultados corroboram com Silva e Giordano (2000) em que relatam que valores abaixo de $350 \mathrm{mg} \%$ de ácido cítrico aumentam a proliferação de microrganismos nos produtos. Moretti et al. (2000) relatam que o grau de maturação, além da presença eventual dos patógenos originários do campo, pode também proporcionar uma rápida proliferação de fungos, sendo que com o avançar do grau de maturação, a tendência é que haja naturalmente o aumento dos parâmetros ATT e pH.

\section{CONCLUSÕES}

Os parâmetros de ATT, SST, pH e SST/ATT não foram alterados pelos tratamentos T4 (copaíba) e T5 (alecrim), enquanto os demais tratamentos apresentaram alteração principalmente na ATT e pH durante o período de armazenamento.

Os tratamentos T5 e T6 apresentaram melhores resultados para controle do grau de maturação, sendo, portanto indicados para esta finalidade, porém, sugere-se que novos estudos sejam realizados a fim 
de determinar se a aplicação dos óleos essenciais altera o sabor dos frutos, bem como determinar doses de aplicação para sua recomendação.

A aplicação dos óleos essenciais não foi eficiente no controle de podridão pós-colheita em frutos de tomate, sendo que os tratamentos T2, T3 e T4 apresentaram maior incidência de podridão, ou seja, alteraram parâmetros importantes como a ATT, que contribui para a proliferação de patógenos. Embora os tratamentos não tenham apresentado controle, o T5 se destaca como potencial, visto que apresentou menor AACPD entre os demais e não alterou os parâmetros de qualidade importantes para o mercado consumidor e que contribuem para o aumento da vida útil de prateleira.

\section{REFERÊNCIAS}

ABREU, M. J.; FERNANDES, T.. Manual de Boas Práticas: Tomate. Porto: ESB/UCP, 2001.

AGRIANUAL. Agrianual 2015: Anuário da agricultura brasileira. São Paulo: FNP Consultoria, 2015.

ALBUQUERQUE, J. M.. Plantas medicinais de uso popular. Brasília: ABEAS/MEC, 1989.

ALMEIDA, C.. Determinação da firmeza e cor do tomate (Lycopersicum esculentum Mill), visando o estabelecimento de correlações entre medidas sensoriais e físicas ao longo do tempo de maturação. Dissertação (Mestrado em Engenharia Agrícola) - Universidade de Campinas, Campinas, 1995.

ALQAREER, A.; ALYAHYA, A.; ANDERSSON, L.. The effect of clove and benzocaine versus placebo as topical anesthetics. Journal of Dentistry, v.34, p.747-50, 2006. DOI: http://doi.org/10.1016/j.jdent.2006.01.009

AL-TURKI, A. I.; EL-ZINEY, M. G.; ABDEL-SALAM, A. M.. Chemical and anti-bacterial characterization of aqueous extracts of oregano, marjoram, sage and licorice and their application in milk and labneh. Journal of Food Agriculture and Environment, v.6, p.39-44, 2008.

AMORIM, L.. Avaliação de Doenças. In: BERGAMIN FILHO, A., KIMATI, H.; AMORIM, L.. Manual de Fitopatologia: Princípios e conceitos. São Paulo: Agronômica Ceres, 1995.

BENATO, E. A.; CIA, P.; SOUZA, N. L.. Manejo de doenças de frutas pós-colheita. Revisão Anual de Patologia de Plantas, Passo Fundo, v.9, p.403-440, 2001.

BETTIOL, W.. Controle biológico de doenças de plantas. Jaguariúna: EMBRAPA CNPDA, 1991.

BIANCHI, P. L. M.; ANTUNES, G. M. L.. Radicais Livres e os Principais Antioxidantes da Dieta. Revista de Nutrição. Campinas, v.12, p.123-130, 1999. DOI: http://doi.org/10.1590/S1415-52731999000200001

BINOTI, R. M.; DALUTO, E. R.; LOPES, R. V.; MAGALHÃES, C. N.; FURLANETO, K. A.; RAMOS, J. A.; DE CARVALHO, L. R.. Radiação (UV-C) na conservação de tomate 'Pizzadoro' orgânico colhido em dois estádios de maturação. Rev. Iber. Tecnología Postcosecha, v.14, n.2, p.204-216, 2013.
BORELLI, R. P.. Caracterização físico-química em póscolheita de diferentes cultivares de tomateiros. Trabalho de Conclusão de Curso (Graduação em Ciências Agrárias e Ambientais) - Universidade Federal de Mato Grosso, Sinop, 2012.

CAMPBELL, C. L.; MADDEN, L. V.. Introduction to plant disease epidemiology. New York: John Wiley \& Sons, 1990.

CANTERI, M. G.; ALTHAUS, R. A.; VIRGENS FILHO, J. S.; GIGLIOTE, E. A.; GODOY, C. V.. SASM-Agri: Sistema para análise e separação de médias em experimentos agrícolas pelos métodos Scott-Knott, Tukey e Duncan. Revista Brasileira de Agrocomputação, Ponta Grossa, v.1, n.2, p. 1824. 2001.

CARVALHO, L. A.; TESSARIOLI NETO, J.. Produtividade de tomate em ambiente protegido, em função do espaçamento e número de ramos por planta. Horticultura Brasileira, Brasília, v.23, p.986-989, 2005. DOI: http://doi.org/.1590/S0102-05362005000400025

CARVALHO, J. L.; PAGLIUCA, L. G.. Tomate, um mercado que não para de crescer globalmente. Hortifruti Brasil, Piracicaba, n.58, p.6-14, 2007.

CARVALHO, J. B.; SCHWAN-ESTRADA, K. R. F ; BONALDO, S. M.; CRUZ, M. E. S.; CARLOS, M.; STANGARLIN, J. R.. Fungitoxicidade de Cymbopogon citratus e Cymbopogon martinii a Colletotrichum gloeosporioides em frutos de pimentão. Revista Brasileira de Plantas Medicinais, v.10, p.88-93, 2008.

CARLOS, M.; SCHWAN-ESTRADA, K. R. F.; TERUMI, A.; BONALDO, S. M.; MESQUINI, R. M.; CARVALHO, J. B.; STANGARLIN, J. R.. Efeito de extrato bruto e óleo essencial de Achillea millefolium em desenvolvimento in vitro de Corynespora cassiicola e proteção de pepino a mancha de corinespora. Arquivos do Instituto Biológico, v.77, p.309$316,2010$.

CASCON, V.; GILBERT, B.. Characterization of the chemical composition of oleoresins of Copaifera guianensis Desf., Copaifera duckei Dwyer and Copaifera multijuga Hayne. Phytochemistry, v.55, p.773-778, 2000. DOI: http://doi.org/10.1016/S0031-9422(00)00284-3

CECCHI, H. M.. Fundamentos teóricos e práticos em análise de alimentos. Campinas: Unicamp, 1999. 
CHITARRA, M. I. F.; CHITARRA, A. B.. Pós-colheita de frutos e hortaliças: fisiologia e manuseio. Lavras: ESAL/FAEPE, 1990.

CONNER, D. E.. Naturally occurring compounds. In: DAVIDSON P.; BRANEN A. L.. Antimicrobials in foods. New York: Marcel Dekker, 1993. p.441-68.

CUNHA, A. G.. Dicionário histórico das palavras portuguesas de origem tupi. Brasília: Melhoramentos, 1999.

DAMODARAN, S.; PARKIN, K.; FENNEMA, O. R.. Fennema's food chemistry. 4 Ed. Boca Raton: CRC Press, 2008.

DECKER, E. A.. Phenolics: prooxidants or antioxidants?. Nutrition Reviews, v.55, n.11, p.396-407, 1997.

DÍAZ-VICIEDO, R.; HORTELANO, S.; GIRÓN, N.; MASSÓ, J. M.; RODRIGUEZ, B.; VILLAR, A.; DE LAS HERAS, B.. Modulation of anti-inflammatory responses by diterpene acids from Helianthus annuus L. Biochemical and Biophysical Research Communications, v.369, p.761-6, 2008. DOI:

http://doi.org/10.1016/j.bbrc.2008.02.104

DORAN, J. C.; BROPHY, J. J.. Tropical red gums: a source of 1,8-cineole-rich Eucalyptus oil. New Forest, Dordrecht, n.4, p.157-178, 1990.

DUMAS, Y.; DADOMO, M.; DI LUCCA, G.; GROLER, P.. Review: effects of environmental factors and agricultural techniques on atioxidantcontento of tomatoes. J. Sci. Food Agric., v.83, p.369-382, 2003.

ECKERT, J. W.. Role of chemical fungicides and biological agents in postharvest disease control. IN: WILSON, C. L.; CHALUTZ, E.. Biological control of postharvest disease of fruits and vegetables. Kearneysville: USDA, 1991. p.14-30

\section{EMBRAPA HORTALIÇAS. Cultivo do Tomate para Industrialização, 2003.}

FAWZI, E. M.; KHALIL, A. A; AFIFI, A. F.. Antifungal effect of some plant extracts on Alternaria alternata and Fusarium oxysporum. African Journal of Biotechnology, v.8, n.11, p.2590-2597, 2009.

FERNANDES, M. C. A.. Emprego de métodos alternativos de controle de pragas e doenças na olericultura. Horticultura Brasileira, v.18, p.110-112, 2000.

FERREIRA, A. B. H.. Novo dicionário da língua portuguesa. Rio de Janeiro: Nova fronteira, 1988.

FERREIRA, S. M. R.; FREITAS, R. J. S.; LAZZARI, E. N.. Padrão de identidade e qualidade do tomate (Lycopersicon esculentum Mill.) de mesa. Ciência Rural, v.34, n.1, p.329335, 2004. DOI: http://doi.org/10.1590/S010384782004000100054

FERREIRA, D. F.. SISVAR: a computer statistical analysis system. Ciência e Agrotecnologia, Lavras, v.35, n.6, p.10391042, 2011. DOI: http://doi.org/10.1590/\$1413$\underline{70542011000600001}$

FIGUEIREDO, A. S. T.; RESENDE, J. T. V.; PAULA, J. T. de; MEERT, L.; DONA, G.; FARIA, M. V.. Desempenho de linhagens comerciais e experimentais de tomate determinado na região Centro-Sul do Paraná. Horticultura Brasileira, v.30, n.S4507-S4514, 2012.

FILGUEIRA; F. A. R.. Novo manual de olericultura: agrotecnologia moderna na produção e comercialização de hortaliças. 3 ed. Viçosa: Ed UFV, 2008.

FILGUEIRA, F. A. R.. Novo Manual de Olericultura: agrotecnologia moderna na produção e comercialização de hortaliças. Viçosa: UFV, 2000.

GENNARO, A. R.. Remington: The Science and Practice of Pharmacy. 19 ed. Pennsylvania: Mack Publishing Company, 1995.

GIORDANO, L. B.; SILVAM J. B. C.; BARBOSA, V.. Escolha de cultivares e plantio. In: SILVA, J. B. C.; GIORDANO, L. B. Tomate para processamento industrial. Brasília: Embrapa, 2000. p.36-59

GOMES, M. S. O.. Conservação pós-colheita: frutas e hortaliças. Brasília: Embrapa, 1996.

GOMES, A. M. A.; SILVEIRA, E. B.; MARIANO, R. L. L.. Tratamento pós-colheita com cálcio e microrganismos para controle de podridão mole em tomate. Horticultura Brasileira, v.23, n.1, p.108-111, 2005. DOI: http://doi.org/10.1590/S0102-05362005000100023

GRAÇA, A. J. P.. Heterose e capacidade combinatória de linhagens de tomateiro (Solanum lycopersicum L.) prospectadas para dupla finalidade. Dissertação (Mestrado em Tecnologia Agropecuária) - Universidade Federal do Norte Fluminense Darcy Ribeiro, 2013.

HALL III, C. A.; CUPPETT, S. L.. Structure-Activities of Natural Antioxidants. In: ARUOMA, O. I.; CUPPETT S. L.. Antioxidant methodology in vivo and in vitro concepts. Illinois: AOCS PRESS, 1997. p.141-172

HILI, P.; EVANS, C. S.; VENESS, R. G.. Antimicrobial action of essential oils: the effect of dimethylsulphoxide on the activity of cinnamon oil. Letters in Applied Microbiology, v.24, p.269-275, 1997.

ITAKO, A. T.; SCHWAN-ESTRADA, K. R. F.; TOLENTINO JÚNIOR, J. B.; STANGARLIN, J. R.; CRUZ, M.E. S.. Atividade antifúngica e proteção do tomateiro por extratos de plantas medicinais. Tropical Plant Pathology, v.33, n.3, p.241-244, 2008. DOI: http://doi.org/10.1590/S198256762008000300011

KADER, A. A.; MORRIS, L. L.; STEVENS, M. A.; ALBRIGHT H. M.. Composition and flavor quality of fresh market as influenced by some postharvest handling procedures. Journal of the American Society for Horticultural Science, v.103, n.1, p.6-11, 1978

KHACHIK, F.; CARVALHO, L.; BERNSTEIN, P. S.; MUIR, G. J.; ZHAO, D. Y.; KATZ, N. B.. Chemistry, distribution, and metabolism of tomato carotenoids and their impact on human health. Proceedings of the Society for Experimental Biology and Medicine, v.227, p.845-851, 2002.

KLUGE, R. A.; NACHTIGAL, J. C.; BILHALVA, A. B.. Fisiologia e manejo pós-colheita de frutas de clima temperado. $2^{\mathrm{a}} \mathrm{ed}$. Pelotas: UFPel, 2002. 
KNAAK, N.; FIUZA, L. M.. Potencial dos óleos essenciais de plantas no controle de insetos e microrganismos.

Neotropical Biology and Conservation, v.5, p.120-132, 2010. DOI: http://doi.org/10.4013/nbc.2010.52.08

KORUKLUOGLU, M.; SAHAN, Y.; YIGIT, A.. Antifungal properties of olive leaf extracts and their phenolic compounds. Journal of Food Safety, v.28, p.76-87, 2008. DOI: http://doi.org/10.1007/BF03175032

LIMA, M. P.; ZOGHBI, M. G. B.; ANDRADE, E. H. A.; SILVA, T. M. D.; FERNANDES, C. S.. Constituintes voláteis das folhas e dos galhos de Cinnamomum zeylanicum Blume (Lauraceae). Acta Amaz., v.35, n.3, p.363-366, 2005. DOI: http://doi.org/10.1590/S0044-59672005000300009

LIMA, A.; RIBEIRO, A. S.; BONALDO, S. M.. Efeito dos Óleos Essenciais de Syzygium aromaticum e Melaleuca alternifolia sobre isolados de Aspergillus sp.. Scientific Electronic Archives, v.5, p.63-67, 2014.

LOPES, C. A.; ÁVILA, A. C.. Doenças do tomateiro. Brasília: EMBRAPA/CNPH, 2005.

LORINI, A.; BONALDO, S. M.; MENDES, B. L.. Efeito de óleos essenciais no desenvolvimento de patógenos em amêndoas de castanhas-do-brasil. Scientia Agraria Paranaensis, v.15, p.121-126, 2016. DOI: http://doi.org/10.18188/19831471/sap.v15n2p121-126

MANGELS, A. R., HOLDEN, J. M., BEECHER, G. R., FORMAN, M. R., LANZA, E.. Carotenoid content of fruits and vegetables: an evaluation of analytic data. Journal of the American Dietetic Association; v.93, n.3, p.284-296,1993.

MARI, M.; GUIZZARDI, M.. The postharvest phase: emerging technologies for the control of fungal diseases.

Phytoparasitica, v.26, n.1, p.59-66, 1998. DOI: http://doi.org/10.1007/BF02981267

MARTINS, E. R.; CASTRO, D. M.; CASTELLANI, D. C.; DIAS, J. E.. Plantas medicinais. Viçosa: UFV, 1998.

MARTINS, E. R.; CASTRO, D. M.; CASTELLANI, D. C.; DIAS, J. E.. Plantas medicinais. Viçosa: UFV, 2000.

MARTINS-DA-SILVA, R. C. V.. Taxonomia das espécies de Copaifera L. (Leguminosae-Caesalpinioideae) ocorrentes na Amazônia brasileira. Tese (Doutorado) - Universidade Federal do Rio de Janeiro, Rio de Janeiro, 2006.

MARTINEZ-VALVERDE, I.; PERIAGO, M. J.; PROVAN, G.; CHESSON, A.. Phenolic compounds, lycopene and antioxidant activity in commercial varieties of tomato (Lycopersicum esculentum). J. Sci. Food Agric., v.82, p.323330, 2002. DOI: http://doi.org/10.1002/jsfa.1035

MATIELLO, J.; RAASCH, L. D.; BERBER, G. C. M.; TRENTO, R. A.; BONALDO, S. M.. Síntese de fitoalexinas em soja e sorgo por extratos e tinturas pertencentes a três espécies florestais. Revista em Agronegócios e Meio Ambiente, v.9, p.617-633, 2016. DOI: http://doi.org/10.17765/21769168.2016v9n3p617-633

MAY, A.; SUGUINO, E.; MARTINS, A. N.; BARATA, L. E. S.; PINHEIRO, M. Q.. Produção de biomassa e óleo essencial de alecrim (Rosmarinus officinalis L.) em função da altura e intervalo entre cortes. Rev. bras. plantas med., v.12, n.2, p.195-200, 2010. DOI: http://doi.org/10.1590/S1516$\underline{05722010000200011}$

MCGUIRE, R. G.. Reporting of objective color measurements; HortScience, v.27, p.1254-1255, 1992.

MELO, P. C. T.. Melhoramento genético do tomateiro. Campinas: Asgrow, 1989.

MORETTI, C. L.; CALBO, A. G.; HENZ, G. P.. Fisiologia e Manejo pós-colheita. In: SILVA, J. B. C.; GIORDANO, L. B.. Tomate para processamento industrial. Brasília: Embrapa Comunicação para Transferência de Tecnologia/Embrapa Hortaliças, 2000. p.136-143.

MOURA, M. L.; SARGENT, S. A; OLIVEIRA. R. F.. Efeito da atmosfera controlada na conservação de tomates colhidos em estádio intermediário de maturidade. Scientia Agrícola, v.56, n.1, p.135-142, 1999. DOI:

http://doi.org/10.1590/S0103-90161999000100020

NERIO, L. S.; OLIVERO-VERBEL, J.; STASHENKO, E.. Repellent activity of essential oils: a review. Bioresource Technology, v.101, p.372-378, 2010. DOI:

http://doi.org/10.1016/j.biortech.2009.07.048

OLIVEIRA, M. E. B.; BASTOS, M. S. R.; FEITOSA, T.; BRANCO, M. A. A. C.; SILVA, M. G. G.. Avaliação de parâmetros de qualidade físico-químicos de polpas congeladas de acerola, cajá e caju. Ciência e Tecnologia de Alimentos, Campinas, v.19, n.3, p.326-332, 1999.

PASCHOLATI, S. F.. Potencial de Saccharomycescerevisiae e outros agentes bióticos na proteção de plantas contra patógenos. Piracicaba. Tese (Livre Docência) - Escola Superior de Agricultura "Luiz de Queiroz", Universidade de São Paulo, 1998.

PAWAR, V. C.; THAKER, V. S.. In vitro efficacy of 75 essential oils against Aspergillus niger. Mycoses, v.49, n.4, p.316-23, 2006. DOI: http://doi.org/10.1111/j.14390507.2006.01241.x

PORTE, A.; GODOY, R. L. O.. Alecrim (Rosmarinus officinalis L.): propriedades antimicrobiana e química do óleo essencial. Boletim do Centro de Pesquisa e Processamento de Alimentos, v.19, n.2, p.193-210, 2001. DOI: http://doi.org/10.5380/cep.v19i2.1233

RESENDE, J. M.; CHITARRA, M. I.; MALUF, W. R.; CHITARRA, A. B.; SAGGIN JUNIOR, O. J.. Atividade de enzimas pectinametilesterase e poligalacturonase durante $o$ amadurecimento de tomates do grupo multilocular. Hort. Bras., v.22, n.2, p.206-212, 2004. DOI: http://doi.org/10.1590/\$0102-05362004000200009

RICK, C. M.; BUTLER, L.. Cytogenetics of the tomato. Advances Genetics. v.8, p.267-402. 1956. DOI: http://doi.org/10.1016/S0065-2660(08)60504-0

RIGAMONTE-AZEVEDO, O. C.; WADT, P. G. S.; WADT, L. H. O.. Potencial de produção de óleo-resina de copaíba (Copaifera sp.) de populações naturais do sudoeste da Amazônia. Revista Árvore, v.30, n.4, p.583-591, 2006. DOI: http://doi.org/10.1590/S0100-67622006000400011 
ROBBINS, S. R. J.; GREENHALGH, P.. The markets for select herbaceous essential oils. London: Tropical Products Institute, 1979.

RODRIGUEZ-AMAYA, D. B.; KIMURA, M.; AMAYA-FARFAN, J.. Fontes Brasileiras De Carotenóides. Tabela Brasileira de Composição de Carotenoides em Alimentos, 2008.

ROUBACH, R.; GOMES, L. C.; FONSECA, F. A. L.; VAL, A. L.. Eugenol as an efficacious anaesthetic for tambaqui, Colossoma macropomum (Cuvier). Aquaculture Research, v.36, n.11, p.1056-61, 2005. DOI:

http://doi.org/10.1111/j.1365-2109.2005.01319.x

SCHERER, R.; WAGNER, R.; DUARTE, M. C. T.; GODOY, H. T.. Composição e atividades antioxidante e antimicrobiana dos óleos essenciais de cravo-da-índia, citronela e palmarosa. Revista Brasileira de Plantas Medicinais, v.11, n.4, p.442449, 2009. DOI: http://doi.org/10.1590/S1516$\underline{05722009000400013}$

SCHWAN-ESTRADA, K. R. F.; CARVALHO, J. B.; BONALDO, S. M.; CRUZ, M. E. S.; CARLOS, M. M.; STANGARLIN, J. R.. Fungitoxicidade de Cymbopogon citratus e Cymbopogon martinii a Colletotrichum gloeosporioides em frutos de pimentão. Revista Brasileira de Plantas Medicinais, v.10, p.88-93, 2008.

SEOL, D. W.; LEE, J.; IM, S. Y.; PARK, I. S.. Clove oil as an anaesthetic for common octopus (Octopus minor, Sasaki). Aquaculture Research, v.38, n.1, p.45-9, 2007. DOI: http://doi.org/10.1111/j.1365-2109.2006.01622.x

SHIRAHIGE, F. H.; MELO, P. C. T.; MELO, A. M. T.; JACOMINO, A. P.; PURQUERIO, L. F. V.; ROQUEJANI, M. S.. Produtividade e qualidade de tomates Santa Cruz e Italiano em função do raleio de frutos. Hortic. Bras., v.28, n.3, p.292-298, 2010. DOI: http://doi.org/10.1590/S0102-05362010000300009

SILVA, J. B. C.; GIORDANO, L. B.. Tomate para processamento industrial. Brasília: Embrapa Comunicação para Transferência de Tecnologia; Embrapa Hortaliças, 2000.

SILVA, F. H.; OLIVEIRA, M. F.; BRAGA, M.; YOUNG, M. C. M.; BOLZANI, V. S.; CARDOSO-LOPES, E. M.; TORES, L. M. B.. Estudo do óleo essencial e extrato hidrometanólico de Copaifera langsdorffii Desf (Caesalpinaceae) do cerrado e mata atlântica. In: REUNIÃO NACIONAL DA SOCIEDADE BRASILEIRA DE QUÍMICA, 29. Anais. São Paulo: Instituto de Química da USP, 2006.

SILVA, K. B.; ALVES, E. U.; BRUNO, R. L. A.; SANTOS, S. S.; BARROSO, L. M.. Tolerância à dessecação de sementes de Cinnamomum zeylanicum Ness. Semina: Ciências Agrárias, v.33, p.587-594, 2012. DOI: http://doi.org/10.5433/1679$\underline{0359.2012 v 33 n 2 p 587}$

SILVEIRA, N. S. S.; MICHEREFF, S. J.; MARIANO, R. L. R.; TAVARES, L. A.; MAIA, L. C.. Influência da temperatura, período de molhamento e concentração do inóculo de fungos na incidência de podridões pós-colheita em frutos de tomateiro. Fitopatologia Brasileira, v.26, n.1, p.33-38. 2001. DOI: http://doi.org/10.1590/S0100-41582001000100006

SIMIC, A.; SOKOVIC, M. D.; RISTIC, M.; GRUJIC-JOVANOVIC, S.; VUKOJEVIC, J.; MARIN, P. D.. The chemical composition of some Lauraceae essential oils and their antifungal activities. Phytotherapy Research, v.18, p.713-717, 2004. DOI: http://doi.org/10.1002/ptr.1516

SIMÕES, C. M. O.; SCHENKEL, E. P.; GOSMANN, G.. Farmacognosia: da planta ao medicamento. Porto Alegre: UFRGS; Florianópolis: UFSC, 1999.

SIMÕES, C. M. O.; SPITZER, V.. Óleos voláteis. In: SIMÕES, C. M. O.; SCHENKEL, E. P.; GOSMANN, G.. Farmacognosia: da planta ao medicamento. 2 ed. Porto Alegre: Universidade Federal do Rio Grande do Sul, Universidade Federal de Santa Catarina, 2000. p.394-412.

STARZYNSKA, A. J.; STODOLAK, B. Z.; JARNROZ, M. Antioxidant properties of extracts from fermented and cooked seeds of Polish cultivars of Lathyrus sativus. Food Chem., v.109, p.285-92, 2008. DOI:

http://doi.org/10.1016/i.foodchem.2007.12.028

TAVARES, G. M.. Controle químico e hidrotérmico da antracnose em frutos de mamoeiro (Carica papaya L.) na pós-colheita. Dissertação (Mestrado em Fitopatologia) Universidade Federal de Lavras, Lavras, 2004.

VEIGA JUNIOR, V. F.. Controle de qualidade de óleos de copaíba por cromatografia gasosa de alta resolução. Dissertação (Mestrado em Química) - Universidade Federal do Rio de Janeiro, Rio de Janeiro, 1997.

VILELA, N. J.; MACEDO, M. C. Fluxo de poder no agronegócio: o caso das hortaliças. Horticultura Brasileira, v.18, n.2, p.88-94, 2000. DOI: http://doi.org/10.1590/S0102$\underline{05362000000200002}$

VIUDA-MARTOS, M.; RUIZ-NAVAJAS, Y.; FERNANDEZ-LOPEZ, J.; PÉREZ-ALVAREZ, J. A.. Antifungal activities of thyme, clove and oregano essential oils. Journal of Food Safety, v.27, n.1, p.91-101, 2007. DOI: http://doi.org/10.1111/j.17454565.2007.00063.x

ZAMBRANO, J.; MOYEJA, J.; PACHECO, L.. Efecto del estado de madurez en la composición y calidad de frutos de tomate. Agronomia Tropical, v.46, n.1, p.61-72, 1996.

ZAMBOLIM, L.; VALE, F. X. R.; COSTA, H.. Controle integrado das doenças de hortaliças. Viçosa: UFV, 1997.

ZEGARSKA, Z.; AMAROWICE, R.; KARAMAC, M.; RAFALOWSKI, R.. Antioxidative effect of Rosemary ethanolic extract on butter. Milchwissenschaft, v.51, p.195-198, 1996. 